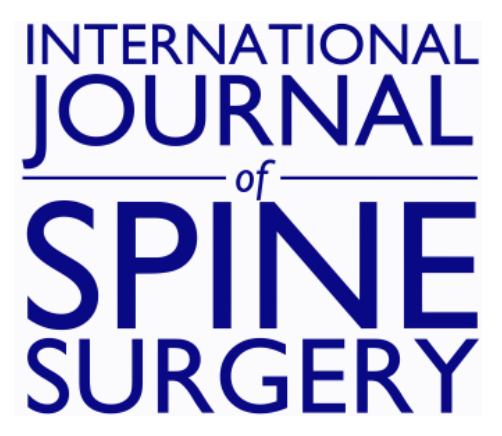

\title{
Anatomical Variations in the Origin of the Lumbar Artery: A Cadaveric Study Augmented by CT Findings
}

Thomas Mombo Amuti, Ibsen Henric Ongidi, Innocent Peter Ouko, Dennis Nick, Joseph Mageto, Laura Ocholla, Beda Olabu and Julius Alexander Ogeng'o

Int J Spine Surg 2021, 15 (5) 906-914

doi: https://doi.org/10.14444/8118

http://ijssurgery.com/content/15/5/906

This information is current as of April 26, 2023.

Email Alerts Receive free email-alerts when new articles cite this article. Sign up at:

http://ijssurgery.com/alerts

The International Journal of Spine Surgery

2397 Waterbury Circle, Suite 1,

Aurora, IL 60504, Phone: +1-630-375-1432 


\title{
Anatomical Variations in the Origin of the Lumbar Artery: A Cadaveric Study Augmented by CT Findings
}

\author{
THOMAS MOMBO AMUTI, BSC, IBSEN HENRIC ONGIDI, BSC, INNOCENT PETER OUKO, BSC, \\ DENNIS NICK, JOSEPH MAGETO, LAURA OCHOLLA, BEDA OLABU, BSC, MBCHB, MSC, MMED, \\ JULIUS ALEXANDER OGENG'O, BSC, MBCHB, MD, PHD, DSC \\ Department of Human Anatomy, School of Medicine, University of Nairobi, Nairobi, Kenya
}

\begin{abstract}
Background: Anatomical variations of lumbar arteries predispose them to iatrogenic injury during endovascular intervention or surgery. Due to limited morphological data on lumbar arteries in our setting, we aimed to determine their variant anatomy among Kenyans.

Methods: We performed the study on 90 cadaveric specimens and 120 computed tomography (CT) scans. Cadavers were dissected to expose the aorta and the lumbar arteries emerging from them. The number, origins, location relative to the vertebral bodies, and relations to aortic bifurcation were determined in cadavers and CT scans. Data were analyzed using SPSS (version 21.0).

Results: On average, $3(3 / 90$ [3.3\%]), $4(63 / 90$ [70\%]) or $5(24 / 90$ [26.7\%]) pairs of lumbar arteries were observed among the cadaveric specimens, whereas $4(100 / 120[83.3 \%])$ or $5(20 / 120[16.7 \%])$ pairs were observed in CTs. Differences in the number of pairs observed in the cadaveric versus CT study were not statistically significant $(P=.542)$. There were no sex differences in the number of lumbar artery pairs observed in CT scans $(P=.178)$. The first 3 lumbar artery pairs had a single-origin, whereas the fourth lumbar artery had a common-stem origin. The first, second, and third lumbar arteries mostly originated at the upper third of their respective vertebral bodies. The fourth lumbar artery predominantly originated at the lower third.

Conclusion: Our study's findings show unique variation in the lumbar arteries' relation to the vertebral bodies and the distances between artery pairs.

Level of Evidence: IV (cross-sectional study).

Clinical Relevance: Variations in the anatomy of the lumbar arteries should be taken into consideration, especially in surgical or interventional procedures to avoid inadvertent injury of the vessels.

Lumbar Spine

Keywords: lumbar arteries, anatomic variation, computed tomography, aorta, spine, surgery
\end{abstract}

\section{INTRODUCTION}

Lumbar arteries are the principal arteries supplying the lower back region. Standard literature describes them as 4 pairs in number, bilateral, and arising posterolaterally from the aorta. ${ }^{1}$ A fifth lumbar artery is occasionally present, arising either from the aorta or the middle sacral artery. The lumbar arteries course posterolaterally on the 4 upper lumbar vertebral bodies, over which they divide into anterior, posterior, and spinal components. The spinal component enters the spinal canal and supplies the spinal cord, intervertebral discs, and related structures. The anterior and posterior components run past the sympathetic trunks into the gaps between the lumbar transverse processes to supply the anterolateral and posterior body wall, respectively.
Studies have documented population variations in lumbar artery anatomy in the Sri-Lanka, Turkey, and Canadian population. ${ }^{2-4}$ These include variations in the number of artery pairs (ranging from 1 to 5), the pattern of origin (either as a common stem or single stem), and the relation of its origin to the lumbar vertebra. The distances between lumbar artery origins also vary. ${ }^{5}$ Variations of lumbar arteries have been linked to lower back pains $(\mathrm{LBP})^{6}$ and iatrogenic injury of the vessel during surgical repairs of para-esophageal hernias. ${ }^{4}$

LBP is a prevalent musculoskeletal condition in both developed and developing nations. A systematic review and meta-analysis revealed that Africans had a lifetime LBP prevalence of $47 \% \quad(95 \%$ confidence interval [CI]: 37-58) and point prevalence of $39 \%$ (95\% CI: 30-47), which was higher 
than the global LBP prevalence. ${ }^{7}$ Apart from the existing ergonomic-related factors, patients with LBP may have variations in the lumbar arteries, including missing arteries and narrow vessels. ${ }^{6}$ Insufficient arterial blood flow may be an underlying factor for LBP symptoms in such cases.

Additionally, lumbar arteries are often affected by atherosclerosis concurrently with the abdominal aorta. Occlusion of lumbar arteries by atherosclerotic plaques is associated with degenerative disk disease, facet arthritis, and spinal cord ischemia, leading to lumbar angina and spinal dysfunction. ${ }^{8,9}$ Anatomical variation influences the probability of occlusion due to atherosclerosis, with higher rates observed when lumbar artery pairs arise from a common stem. ${ }^{4}$ Occlusion is also more common in the lumbar arteries that originate at a lower position from the aorta.

Anatomic variations of the lumbar artery have also been linked with an iatrogenic injury during endovascular procedures for abdominal aortic and lumbar artery aneurysms. ${ }^{10}$ There is difficulty accessing these vessels during procedures such as embolization in the treatment of vertebral body tumors, and aortic stent graft placements, ${ }^{2}$ emphasizing the need for morphometry. In the process of stent-graft placement for abdominal aortic aneurysm, bridging of lumbar arteries may present with the sequelae of the spine and lower back ischemia. ${ }^{11}$ In some instances, serious complications such as postoperative endoleaks are reported from aortic stent graft placements. ${ }^{12}$ The vertebral bodies are also used as landmarks during arteriographies. Understanding the lumbar arteries' relation to the vertebra is paramount to avoiding incorrect contrast media injection into lumbar vessels.

Laufman et $\mathrm{al}^{2}$ stated that standard textbook descriptions of the lumbar artery fall short of the anatomical information necessary to study means of lessening the risk of injury to the vessel. Other workers have also noted that there is a deficiency in studies assessing the lumbar artery. ${ }^{10,13}$ Studies evaluating the lumbar arteries' anatomy using computed tomography (CT) have revealed that vessels may not be visualized in some cases. ${ }^{5,12}$ The arteries may especially not be visible in the elderly in whom factors such as atherosclerosis reduce the luminal diameter and flow of contrast into the arterial lumen. Therefore, studying the vessels' normal anatomy from cadaveric specimen may help augment the CT and help the interpreter make better decisions in case of variations. Further, there is a paucity of data, especially in the African setting, and thus we aimed to determine the lumbar artery's variant anatomy among Kenyans.

\section{MATERIALS AND METHODS}

We conducted a retrospective descriptive crosssectional study that combined both cadaveric and radiographic analysis of lumbar vessels. A total of 90 male cadavers were obtained from the Department of Human Anatomy of the University of Nairobi. Approval for cadaveric materials is provided in the Human Anatomy Act Cap 249 (1967) AND 252 (1958), respectively, in the Kenyan constitution. For CT studies, 120 scans which were equally from both male and female patients were sought from the Kenyatta National Hospital Radiology Department (Figure 1). Permissions to use the scans were obtained from the Kenyatta National Hospital and ethical approval was waived because this was a retrospective study. The CT scans were interpreted by the same radiologists in the institution between November 11, 2019, and November 30, 2020.

We excluded those who had a previous back injury or surgery from the study. Similarly, those with metastatic lesions affecting the lumbar arteries, abdominal aortic aneurysms, vascular malformation of lumbar arteries, and lumbosacral transitional vertebra were excluded. The ages were documented where necessary for purposes of analysis.

\section{Dissection of the Cadaveric Specimen to Expose the Lumbar Vessels}

First, the abdominal aorta was identified during routine abdominal dissection and in postmortems. A midline incision was made on the aorta to view the ostia of the lumbar arteries. The renal arteries were located as branching from the aorta laterally and coursing toward the kidneys. Because they originate at the L1-L2 junction, they served as a landmark to the first and second lumbar arteries. The lumbosacral junction was then identified and used in the numbering of the lower lumbar arteries.

\section{Determining the Number of Lumbar Arteries}

The lumbar arteries that arise opposite the vertebral bodies first, second, third, and fourth vertebrae were 


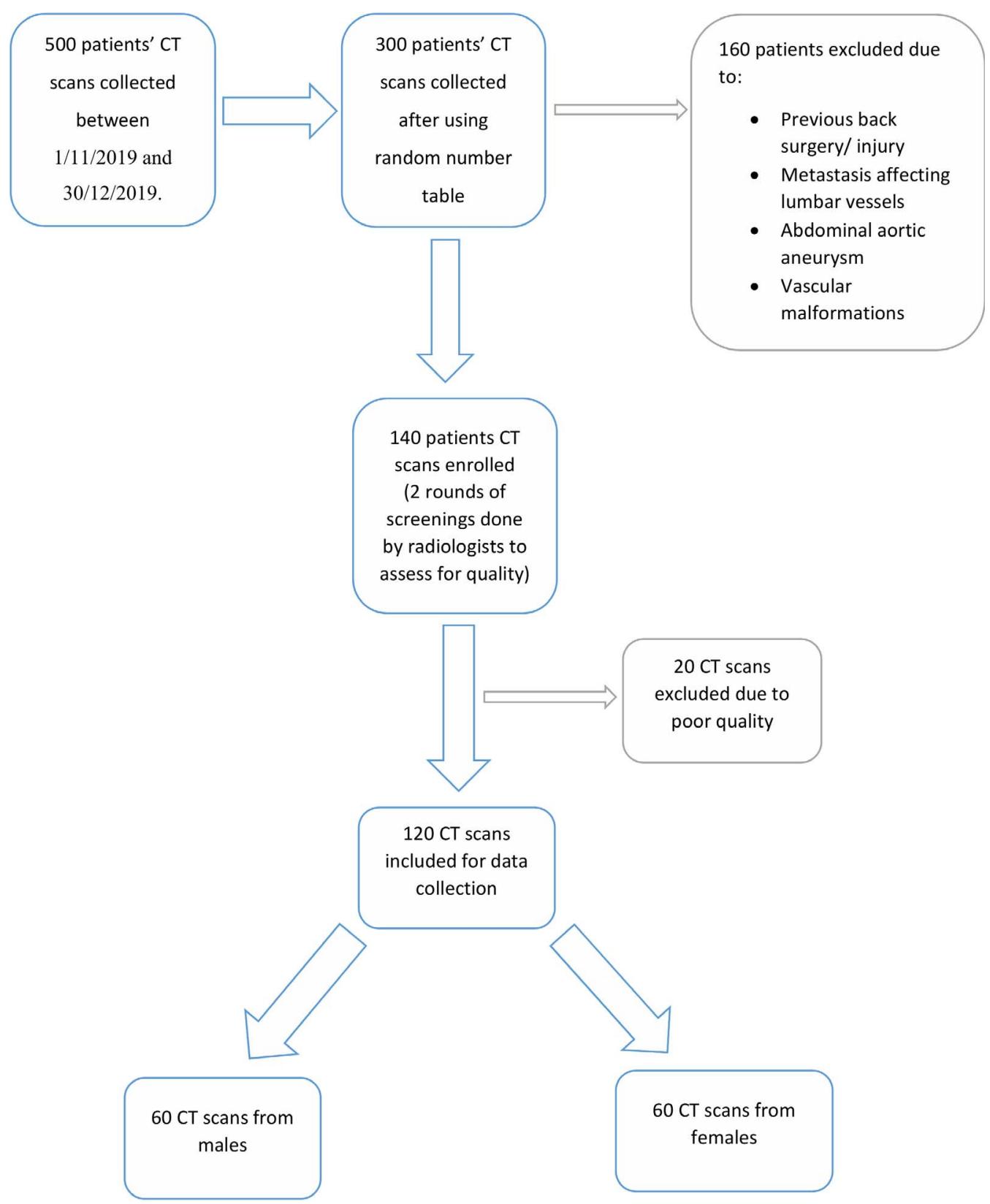

Figure 1. Flow chart showing the selection process of CT scans obtained from the Kenyatta National Hospital Radiology Department.

identified as the first, second, third, and fourth lumbar arteries. Origins were also noted in cases where a fifth lumbar artery or median sacral artery was identified. Any variations in origin of the presence of the arteries were recorded and photographed.

\section{Determining the Pattern of Lumbar Artery Origin}

Once the lumbar arteries were identified, the vessels' origin was determined by observing their ostia from the split-up aorta. The vessels' variations were then documented as either common (in these cases, arteries shared a common ostium) or single (where the arteries on the right and left side originated singly from the aorta, with a distinct ostium for each vessel). All variations were photographed.

\section{Determining the Position of the Lumbar Arteries}

Each lumbar artery's position was measured in the cadavers as the distance from the aortic bifurcation. Additionally, the bifurcation's distance to the left renal vein's inferior border was measured to determine the infrarenal aortic length, which was used to normalize the measurements during analysis. Measurements were made using digital calipers (RCBS Electronic) by 2 independent raters to 


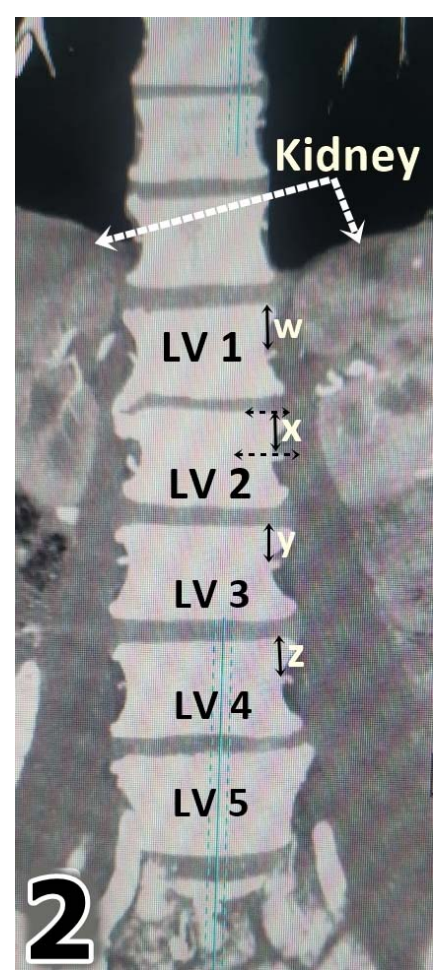

Figure 2. CT showing the measurement of the distances $(\mathrm{W}, \mathrm{X}, \mathrm{Y}, \mathrm{Z})$ between the origin of the lumbar arteries and the top of their respective vertebra. LV, lumbar vertebra.

reduce individual bias. In addition to written records, all specimens were photographed using a Nikon DSLR camera. The relative positions of the vessels and the distance between consecutive lumbar arteries were also plotted out.

\section{CT Specimen}

To further characterize the lumbar arteries' anatomy, we analyzed postcontrast abdominopelvic CT scans from patients presenting to the hospital. All CT scans were taken using a Siemens CT machine (SOMATOM definition AS +128 , Siemens Healthcare GmbH, Germany). Images were obtained using a standardized protocol. Scanning conditions were a voltage of 100 to $140 \mathrm{kV}$, and slice thickness of $0.7 \mathrm{~mm}$. The field of view was 250 to $500 \mathrm{~mm}$ dependent on the patient size with a 512 matrix size. The scans were then imported into a Dicom software program (RadiAnt DICOM Viewer, Medixant, Poznan, Poland) for reformatting, standardizing, and labeling. After that, they were reviewed for analysis of lumbar arteries by 2 radiologists (Figure 1). Determination of the number of artery pairs and the origin patterns was done similarly to that of the cadaveric samples.

\section{Measurement of the Location of Lumbar Artery Origins on the Vertebral Body}

In measuring the lumbar artery's location on the vertebral body, the top of each vertebral body was first identified. Subsequently, the distance of the vessels' origin to the top of their respective vertebrae was determined (Figure 2). The whole vertebral body height was also taken and divided into upper, middle, and lower thirds. The distance or the lumbar artery origins from the top of their respective vertebra was divided by the vertebral body height, then multiplied by 3 to determine whether it lay in the upper, middle, or lower third of the vertebral body.

\section{Statistical Methods}

Measurements obtained were coded and analyzed using SPSS (version 21.0). Variations in the number of arteries, patterns of origin, and position on the vertebral bodies were calculated in percentages. Distances were calculated as means. Shapiro-Wilk test was run to assess data normality, Cronbach $\alpha$ was used to test for reliability, and the MannWhitney $U$ test was used to test sex differences. Side differences were analyzed using the Wilcoxon test. A $P$ value of less than or equal to .05 was considered significant at a $95 \% \mathrm{CI}$.

\section{RESULTS}

In the study, a total of 210 sets of lumbar arteries were assessed. All 90 cadavers were male, whereas the CT study had $60(50 \%)$ males and $60(50 \%)$ females. The ages of the cadavers could not be obtained. However, among the patients who had CT scans, the mean age was 53 years, and the median age was 59 years (16 years-81 years).

\section{Number of Lumbar Arteries}

On average, there were 4 pairs of lumbar arteries noted. Specifically, among the cadaveric specimens, $3(3 / 90[3.3 \%]), 4(63 / 90[70 \%])$, or $5(24 / 90$ [26.7\%]) pairs of lumbar arteries were seen, whereas among the participants who underwent CT, 4 (100/ $120[83.3 \%])$ or $5(20 / 120[16.7 \%])$ pairs were seen (Figure 3A-E). In all cases observed, both cadaveric and CT, all the lumbar arteries occurred in pairs; no unilateral arteries were noted.

Shapiro-Wilk test done to check for normality showed that our data was not normally distributed in cadaveric and CT groups $(P=.0002, .0003$, respectively). Therefore, we used nonparametric 

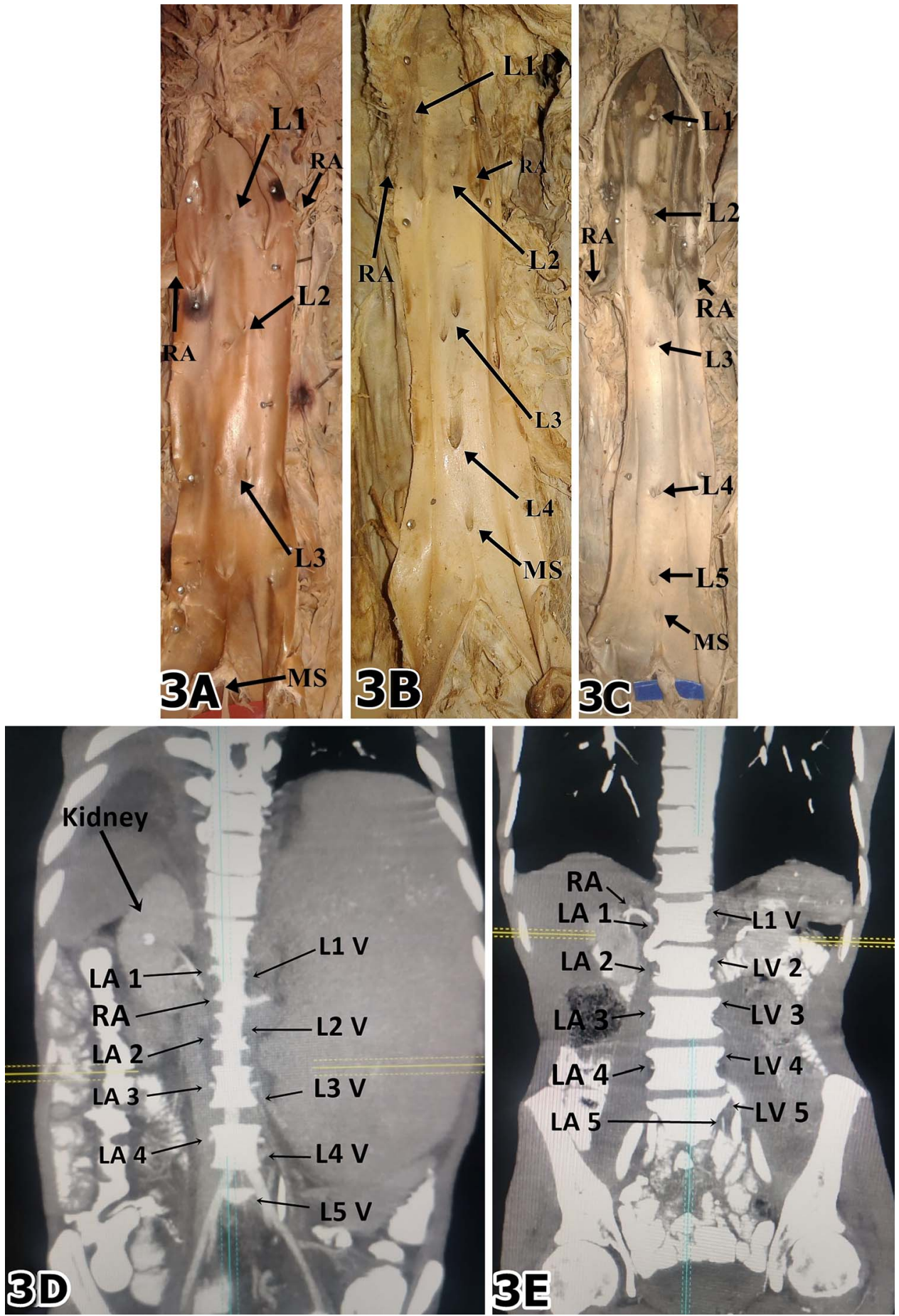

Figure 3. (A) Dissected aorta showing ostia for 3 pairs of lumbar arteries (L1, L2, and L3). (B) Dissected aorta showing ostia for 4 pairs of lumbar arteries (L1, L2, L3, L4). (C) Dissected aorta showing ostia for 5 pairs of lumbar arteries (L1, L2, L3, L4, L5), with the L2 originating below the renal artery. (D) CT scan showing 4 pairs of lumbar arteries (LA 1, LA 2, LA 3, LA 4). (E) CT scan showing 5 pairs of lumbar arteries (LA 1, LA 2, LA 3, LA 4, LA 5). LV, lumbar vertebra; MS, middle sacral artery; RA, renal artery.

tests for further analysis. A Mann-Whitney test showed no statistical differences in the number of lumbar artery pairs observed in the cadaveric versus CT studies $(P=.542)$. Sex differences in the number of lumbar artery pairs were not statistically significant among the CT group $(P=.178)$.

\section{The Pattern of Origin of Lumbar Arteries}

Our study's findings showed that among the first 3 lumbar arteries (L1-L3), the most common pattern of origin was single-origin (a single ostium of right and left lumbar arteries, respectively). In 
Table 1. Table showing the different patterns of the lumbar artery origin.

\begin{tabular}{llc}
\hline Lumbar Artery & \multicolumn{1}{c}{ Pattern } & Frequency, \% \\
\hline L1 & Single-origin & 92 \\
& Common stem origin & 8 \\
L2 & Single-origin & 87 \\
& Common stem origin & 13 \\
L3 & Single-origin & 74 \\
& Common stem origin & 25 \\
L4 & Single-origin & 48 \\
& Common stem origin & 52 \\
L5 & Single-origin & 50 \\
& Common stem origin & 50 \\
\hline
\end{tabular}

contrast, the fourth pair of lumbar arteries mainly originated as a common stem (single ostium) (Table 1).

The Mann-Whitney test did not reveal any significant differences in the lumbar arteries' patterns based on sex $(P=.514, .514,1.00,1.00,1.00$, respectively for L1, L2, L3, L4, L5).

\section{Position of Lumbar Artery Origins in Relation to the Vertebral Body}

All the lumbar arteries were noted to originate on their respective vertebral bodies. Estimating the distance between the vessel's point of origin from the top of their corresponding vertebral body was difficult in the cadaveric study. Therefore, this was done among the CT group. The mean distances were tabulated (Table 2).

The position of the lumbar arteries' origin on either the upper, middle, or lower thirds of their corresponding vertebrae were as tabulated (Table 3). Of note, the L1 to L3 lumbar arteries had a consistent relation to the upper third of their corresponding vertebral bodies. In contrast, the L4 lumbar artery had an origin mostly at the lower third of the L4 vertebral body. The Shapiro-Wilk test revealed that the locations of the origin of the

Table 2. Table showing the vertebral body heights and distances of lumbar arteries from the top of their respective vertebra.

\begin{tabular}{lccc}
\hline Sex & Lumbar & $\begin{array}{c}\text { Vertebral } \\
\text { Body Height, } \\
\text { Mean } \pm \text { SD (mm) }\end{array}$ & $\begin{array}{c}\text { Distance of } \\
\text { Lumbar Artery From } \\
\text { the Top of Vertebra, } \\
\text { Mean } \pm \text { SD (mm) }\end{array}$ \\
\hline Male & L1 & $25.0 \pm 2.2$ & $10.08 \pm 3.44$ \\
& L2 & $25.5 \pm 3.15$ & $12.88 \pm 2.55$ \\
& L3 & $26.1 \pm 4.18$ & $11.13 \pm 4.95$ \\
& L4 & $26.0 \pm 2.22$ & $5.56 \pm 1.30$ \\
Female & L5 & $26.6 \pm 1.45$ & $13.55 \pm 2.37$ \\
& L1 & $24.8 \pm 2.25$ & $13.39 \pm 1.67$ \\
& L2 & $25.3 \pm 1.62$ & $12.35 \pm 1.05$ \\
& L3 & $25.9 \pm 3.56$ & $8.22 \pm 4.41$ \\
& L4 & $25.8 \pm 2.88$ & $6.37 \pm 2.36$ \\
& L5 & $26.2 \pm 3.45$ & $12.35 \pm 1.25$ \\
\hline
\end{tabular}

Table 3. Locations of the origin of the lumbar arteries on the vertebral bodies.

\begin{tabular}{lcc}
\hline Lumbar Artery & Location on Vertebra & Frequency, \% \\
\hline L1 & Upper $1 / 3$ & 100 \\
& Middle $1 / 3$ & 0 \\
L2 & Lower $1 / 3$ & 0 \\
& Upper $1 / 3$ & 100 \\
& Middle $1 / 3$ & 0 \\
L3 & Lower $1 / 3$ & 0 \\
& Upper $1 / 3$ & 100 \\
& Middle $1 / 3$ & 0 \\
L4 & Lower $1 / 3$ & 0 \\
& Upper $1 / 3$ & 0 \\
L5 & Middle $1 / 3$ & 25 \\
& Lower $1 / 3$ & 75 \\
& Upper $1 / 3$ & 90 \\
& Middle $1 / 3$ & 10 \\
& Lower $1 / 3$ & 0 \\
\hline
\end{tabular}

lumbar arteries on the vertebral bodies were not normally distributed $(P=.003, .011, .004, .033, .000$, respectively). Further, sex-related differences were then assessed using the Mann-Whitney test, which did not reveal any statistically significant differences among the lumbar arteries $(P=1.000,1.000,1.000$. 1.000 for L1, L2, L3, L5, respectively); apart from L4 $(P=.039)$.

\section{The Distance From the Aortic Bifurcation and Between Lumbar Artery Pairs}

The lumbar artery origins' distance from the aortic bifurcation and the infrarenal aortic lengths could only be done among the cadaveric group. The average infrarenal aortic length was $111 \mathrm{~mm} \pm 5.4$ $\mathrm{mm}$. The relative distances of the lumbar artery origins measured from the aortic bifurcation were tabulated (Table 4). The Cronbach $\alpha$ value between the 2 raters for this measurement was 0.88 . There was also no significant difference noted among the right and left sides $(P=.306, .149, .078, .058, .351$,

Table 4. Distances of the origins of the lumbar arteries from the aortic bifurcation.

\begin{tabular}{lcccr}
\hline \multirow{5}{*}{} & \multicolumn{3}{c}{$\begin{array}{c}\text { Distance As Measured From } \\
\text { the Aortic Bifurcation, mm }\end{array}$} \\
\cline { 3 - 5 } Side & Lumbar & $\begin{array}{c}\text { Mean } \pm \text { Standard } \\
\text { Deviation }\end{array}$ & Range & Median \\
\hline \multirow{2}{*}{ Right } & Artery & $130.64 \pm 13.50$ & $114.00-162.00$ & 128.80 \\
& L1 & $97.23 \pm 10.88$ & $68.00-111.00$ & 98.50 \\
& L2 & $72.60 \pm 19.50$ & $6.50-111.00$ & 70.30 \\
& L3 & $53.36 \pm 18.08$ & $6.50-111.00$ & 50.75 \\
\multirow{3}{*}{ Left } & L4 & $44.78 \pm 17.11$ & $9.60-60.50$ & 51.15 \\
& L5 & $133.28 \pm 13.99$ & $114.00-162.90$ & 131.50 \\
& L1 & $98.28 \pm 10.27$ & $68.00-111.00$ & 100.70 \\
& L2 & $74.90 \pm 16.94$ & $31.50-111.00$ & 74.20 \\
& L3 & $54.94 \pm 17.76$ & $6.50-111.00$ & 52.75 \\
& L4 & $47.85 \pm 11.89$ & $26.50-60.50$ & 51.15 \\
\hline
\end{tabular}


Table 5. Table showing the distances between consecutive lumbar artery pairs.

\begin{tabular}{lcc}
\hline Side & Lumbar Artery Pairs & $\begin{array}{c}\text { Distance Between } \\
\text { Lumbar Artery Pairs, } \\
\text { Mean } \pm \text { SD, mm }\end{array}$ \\
\hline Right & L1-L2 & $33.40 \pm 16.31$ \\
& L2-L3 & $24.63 \pm 17.31$ \\
& L3-L4 & $19.24 \pm 18.26$ \\
Left & L4-L5 & $41.41 \pm 22.34$ \\
& L1-L2 & $35.01 \pm 15.50$ \\
& L2-L3 & $23.38 \pm 15.85$ \\
& L3-L4 & $19.95 \pm 17.54$ \\
& L4-L5 & $38.99 \pm 22.33$ \\
\hline
\end{tabular}

respectively for $\mathrm{L} 1, \mathrm{~L} 2, \mathrm{~L} 3, \mathrm{~L} 4$, and $\mathrm{L} 5$, respectively).

The distance between each lumbar artery pair was calculated and tabulated (Table 5). The first and second lumbar artery pairs consistently had the largest interval. The artery pairs were not equidistant. There were no statistically significant side differences for the distances between the lumbar artery origins $(P=.276, .247, .560, .350$, respectively for the L1-L2, L2-L3, L3-L4, and L4-L5 intervals, respectively).

\section{DISCUSSION}

In this study, the morphology of lumbar arteries from 210 subjects was assessed, of which 90 were cadaveric samples, whereas 120 were CT scans. Our sample size was generally similar to other studies that have been done to evaluate the same (Table 6).

\section{Number of Lumbar Arteries}

There were 4 pairs of lumbar arteries noted on average in both the cadaveric and CT groups in this study. Our findings are comparable with those reported in studies done in Chicago, ${ }^{2}$ Turkey, ${ }^{10}$ Japan, ${ }^{12}$ Indiana, ${ }^{14}$ Canadian, ${ }^{5}$ and Sri-Lanka. ${ }^{4}$ Lumbar vessels often supply the corresponding lumbar vertebra. ${ }^{10}$ Their variations have been linked to LBP, most often when some arteries are missing. ${ }^{6}$ Kauppila and Tallroth ${ }^{6}$ discovered that
$88 \%$ of LBP patients had 1 or more missing artery pairs. Studies in Kenya and Africa, in general, show a significant prevalence and associated burden of LBP. $^{7}$ Therefore, it is plausible that some of these LBPs are attributable to anatomical variations of the lumbar artery vessel.

\section{The Pattern of Origin of Lumbar Arteries}

Lumbar arteries can either originate from the aorta singly ( 2 separate ostia from the aorta) or as a common trunk (single ostia from the aorta). Our findings observed that the most common pattern was single-origin for the first 3 lumbar arteries, whereas the fourth lumbar artery predominantly originated as a common stem. Iwamoto et al, ${ }^{12}$ in their study among the Japanese population, noted the prevalence of common trunks to be $2.4 \%, 9.5 \%$, $11 \%$, and $23 \%$ for the first to the fourth lumbar arteries, respectively. Laufman et $\mathrm{al}^{2}$ noted a $2 \%$ to $6 \%$ prevalence of common origin (single ostia) that was marked in the lower lumbar vessels, with their incidence being most significant at L5 (20\%). Baniel et $\mathrm{al}^{14}$ noted a $15 \%$ prevalence of common trunk origin of the lumbar vessels in the Indiana populace, whereas Beveridge et $\mathrm{al}^{5}$ stated this in $16 \%$ of their subjects. In the Sri-Lanka populace, Karunanayake et $\mathrm{al}^{4}$ observed that in 1 case, the first lumbar arteries originated as a common stem, the second lumbar arteries originated as a common stem in $2 \%$, third lumbar arteries in $3 \%$, and the fourth lumbar arteries in $11 \%$. The only case noted of a fifth lumbar artery in the study also originated as a common trunk.

The formation of common trunks of the lumbar arteries had been shown to have an embryological basis, as suggested by Beveridge et $\mathrm{al}^{5}$ and Şeker et al. ${ }^{10}$ The dorsal intersegmental arteries, which later become the lumbar arteries, may fuse to form a common trunk during the dorsal aortae's fusion sometime in the third to seventh week of gestation. Variations in the pattern of origin of the lumbar

Table 6. Table summarizing demographics from past studies.

\begin{tabular}{|c|c|c|c|c|}
\hline Study & Type of Study & Sample Size & Sex Distribution & Age Distribution \\
\hline Laufman et $\mathrm{al}^{2}$ & Cadaveric & 50 & - & - \\
\hline Şeker et $\mathrm{al}^{10}$ & Cadaveric (Fetuses) & 120 & 50 males, 70 females & - \\
\hline Iwamoto et $\mathrm{al}^{12}$ & $\mathrm{CT}$ & 84 & 51 males, 33 females & $36-89 \mathrm{y}$; mean $64 \mathrm{y}$ \\
\hline Baniel et $\mathrm{al}^{14}$ & Cadaveric & 72 & - & - \\
\hline Beveridge et $\mathrm{al}^{5}$ & Cadaveric and CT & $22 ; 41$ respectively & - & $\begin{array}{l}\text { Cadaver }-76.6 \text { y } \\
\mathrm{CT}-71.6 \mathrm{y}\end{array}$ \\
\hline Karunanayake et $\mathrm{al}^{4}$ & Cadaveric & 109 & 62 males, 47 females & 40-90 y; mean $70.1 \mathrm{y}$ \\
\hline Present study & Cadaveric and CT & $30 ; 24$ respectively & 42 males, 12 females & $16-81 \mathrm{y}$; mean $53 \mathrm{y}$ \\
\hline
\end{tabular}


vessels have been shown to bear clinical significance. Connections exist between the contralateral branches of lumbar vessels of the right and left sides. If there is an obstruction of a lumbar artery on 1 side, the other artery can serve as a complementary conduit. When lumbar artery pairs arise from 1 stem, blood flow to both sides can be obstructed easily in atherosclerotic disease, and clinical problems such as LBP may occur. ${ }^{4}$ Most obstructions have been linked to atherosclerosis, which has a significant prevalence in our setting. Therefore, because most of the L4 and L5 arteries supplying the lower back in our study originate as common stems, persons may be prone to LBP in the setting of atherosclerosis.

Several technical maneuvers help prevent intraoperative injury to the lumbar vessels by the surgeon operating in the retroperitoneum. When approaching a vessel that has a bifurcation or trifurcation, each branch may be ligated separately. If both components are ligated simultaneously, the ligature may slip off and cause considerable bleeding. In our setting, care must be taken during such procedures to ligate each vessel separately instead of the common trunk. ${ }^{14}$ The presence of common truncal origin of lumbar arteries has also been linked to increased failure to inject contrast media to the vessels due to difficulty identifying them. ${ }^{2}$

\section{Position of Lumbar Artery Origins in Relation to the Vertebral Body}

Other than the fourth and fifth lumbar arteries, the other lumbar vessels in our setting were located on the upper third of their respective vertebra. Our findings were similar to Laufman et $\mathrm{al}^{2}{ }^{2}$ who found that ostia were situated in the middle thirds in only $2 \%$ of first lumbar arteries and $6 \%$ of second lumbar arteries. The lumbar artery's position on the vertebral body is essential, especially during the injection of contrast media, where the commonly invaded areas are the middle thirds of the vertebral bodies. ${ }^{2}$ Since most of our cases had vessel origins at the upper third for the upper lumbar arteries, care should be taken during procedures around the area to avoid inadvertent injury.

\section{The Distance From the Aortic Bifurcation and Between Lumbar Artery Pairs}

Our study's findings summarized the distances of the lumbar arteries from the aortic bifurcation. These measurements may be useful as an approx- imation for lumbar arteries' location during surgeries. Our results showed that the vessels did not have a constant distance between consecutively numbered arteries. Our results were inconsistent with those reported by Beveridge et $\mathrm{al}^{5}{ }^{5}$ in whose populace they noted a relatively constant distance between consecutive lumbar artery pairs.

In a clinical setting, an appreciation of the possible variations may be necessary for the successful management of back conditions and the prevention of intraoperative bleeds that compromise the visual field and, in some cases, the patient. ${ }^{10}$ Additionally, lumbar artery variations predispose to endoleak development after endovascular abdominal aortic aneurysm repair, leading to the aneurysm's rupture despite a seemingly adequate repair. Clarification of lumbar arterial anatomy may help predict the endoleak occurrence and ultimately promote endoleak prevention and treatment.

\section{Limitations}

Because all the cadavers we obtained were male, a test assessing sex difference was not carried out in the cadaveric study. Similarly, age-related differences could not be evaluated due to the small sample size with high variability ages. We recommend that further investigations with larger samples are done to corroborate the findings of this study.

\section{CONCLUSIONS}

In conclusion, there were 3 to 5 pairs of lumbar arteries noted in our setting. The most common origin pattern was single-origin among the first 3 lumbar arteries and common-stem origin in the fourth lumbar artery. The first, second, and third lumbar arteries mostly originated at the upper third of their respective vertebral bodies. The fourth lumbar artery predominantly originated at the lower third. A difference was noted in the relation of lumbar artery origins to the vertebra in our study compared with studies in other populations. These should be taken into consideration, especially in procedures involving these vessels to avoid inadvertent injury.

\section{ACKNOWLEDGMENTS}

Ethical approval for this study is provided for by the Human Anatomy Act CAP 249 of the Kenyan Constitution. CT investigations were done under the 
permission of the Department of Radiology of the Kenyatta National Hospital. All procedures were performed following the ethical standards laid down in the 1964 Declaration of Helsinki and subsequent revisions.

\section{REFERENCES}

1. Standring S, Gray H. Gray's Anatomy: The Anatomical Basis of Clinical Practice. 41st ed. Churchill Livingstone: Elsevier; 2015.

2. Laufman $H$, Berggren RE, Finley $T$, Anson BJ. Anatomical studies of the lumbar arteries with reference to the safety of translumbar aortography. Ann Surg. 1960;152(4):621. https://doi.org/10.1097/00000658-196010000-00007

3. Arslan M, Comert A, Acar HI, et al. Surgical view of the lumbar arteries and their branches: an anatomical study. Oper Neurosurg. 2011;68(suppl 1):16-22. https://doi.org/10.1227/ NEU.0b013e318205e307

4. Karunanayake AL, Pathmeswaran A. Anatomical variations of lumbar arteries and their clinical implications: a cadaveric study. Int Sch Res Notices. 2013. https://doi.org/10. $5402 / 2013 / 154625$

5. Beveridge TS, Power A, Johnson M, Power NE, Allman BL. The lumbar arteries and veins: quantification of variable anatomical positioning with application to retroperitoneal surgery. Clin Anat. 2015;28(5):649-660. https://doi.org/10.1002/ ca. 22504

6. Kauppila LI, Tallroth K. Postmortem angiographic findings for arteries supplying the lumbar spine: their relationship to low-back symptoms. J Spinal Disord. 1993;6(2):124-129.

7. Morris LD, Daniels KJ, Ganguli B, Louw QA. An update on the prevalence of low back pain in Africa: a systematic review and meta-analyses. BMC Musculoskelet Disord. 2018;19(1):196. https://doi.org/10.1186/s12891-018-2075-x

8. Beckworth WJ, Holbrook JF, Foster LG, Ward LA, Welle JR. Atherosclerotic disease and its relationship to lumbar degenerative disk disease, facet arthritis, and stenosis with computed tomography angiography. PM R. 2018;10(4):331337. https://doi.org/10.1016/j.pmrj.2017.09.004

9. Kauppila LI. Atherosclerosis and disc degeneration/low- back pain-a systematic review. Eur J Vasc Endovasc Surg. 2009;37(6):661-670. https://doi.org/10.1016/j.ejvs.2009.02.006

10. Şeker M, Çiçekcibaşi AE, Salbacak A, Büyükmumcu M. A morphometric study and variations on the lumbar arteries of human fetuses. Ann Anat. 2005;187(2):135-140. https://doi.org/ 10.1016/j.aanat.2004.08.002

11. Du Toit DF, Saaiman A. Anatomical importance of infrarenal aortic branches in conventional and endovascular surgery: a review. Clin Anat. 2000;13(1):54-62. https://doi.org/10. 1002/(SICI)1098-2353(2000)13:1<54::AID-CA6>3.0.CO;2-X

12. Iwamoto S, Takao S, Harada M. Visualization of lumbar artery variations by contrast-enhanced multi-detector row computed tomography. J Med Investig. 2016;63(1.2):45-48. https://doi.org/10.2152/jmi.63.45

13. Espahbodi S, Humphries KN, Doré CJ, et al. Colour doppler ultrasound of the lumbar arteries: a novel application and reproducibility study in healthy subjects. Ultrasound Med Biol. 2006;32(2):171-182. https://doi.org/10.1016/j.ultrasmedbio. 2005.11.006

14. Baniel J, Foster RS, Donohue JP. Surgical anatomy of the lumbar vessels: implications for retroperitoneal surgery. $J$ Urol. 1995;153(5):1422-1425. https://doi.org/10.1016/S00225347(01)67418-4

Disclosures and COI: The authors received no funding for this study and report no conflicts of interest.

Corresponding Author: Ongidi Ibsen Henric, BSc, Department of Human Anatomy, School of Medicine, University of Nairobi, PO Box 30197, 00100 Nairobi, Kenya. Phone: 020-4-915005; Mobile: +254-7-00930369; Fax: 254-2-2725102; Email: ibsenongidi@students.uonbi.ac.ke.

Published 3 December 2021

This manuscript is generously published free of charge by ISASS, the International Society for the Advancement of Spine Surgery. Copyright (C) 2021 ISASS. To see more or order reprints or permissions, see http://ijssurgery.com. 